\title{
New bacilli-based probiotic for aquaculture: efficacy study on Macrobrachium rosenbergii
}

\author{
Angelina Malkova ${ }^{1, *}$, Ivan Evdokimov ${ }^{1}$, Maksim Shirmanov ${ }^{1}$, Alena Irkitova $^{1}$, and Dmitry \\ Dementyev $^{2}$ \\ ${ }^{1}$ EC "Prombiotech", Altai State University, 656049 Lenin Avenue 61, Barnaul, Russian Federation \\ 2"Arsal" LLC, 658839 Gagarina Street 1C, Yarovoe, Russian Federation
}

\begin{abstract}
The data on the study of the effectiveness of a new probiotic based on strains B. toyonensis B-13249 and B. pumilus B-13250 when growing shrimps are presented. The experiments were carried out on a private farm in Kazakhstan. The control group of shrimps, which did not receive the probiotic, completed the molting process on the 28th day of the experiment, and the experimental group - 10 days earlier. It was also found that the probiotic has a positive effect on the hydrochemistry of water in recirculating aquaculture system (RAS). The concentration of ammonium $\left(\mathrm{NH}_{3} / \mathrm{NH}_{4}{ }^{+}\right)$, nitrite $\left(\mathrm{NO}_{2}\right)$ and nitrate $\left(\mathrm{NO}_{3}^{-}\right)$nitrogen in the experimental group did not reach the limit value, in contrast to the control. Based on the obtained results, this probiotic can be recommended for greening aquaculture. The dosage of the probiotic when applied with brine shrimp as feed for shrimp is $1 \mathrm{~g} / 100 \mathrm{~g}$ of dry cysts. The dosage of the probiotic when the RAS is added to the water is $5 \mathrm{~g} / 6001$ of circulating water once a week.
\end{abstract}

\section{Introduction}

Industrial breeding and rearing of aquatic animals (invertebrates and fish) on a large scale is accompanied by the spread of various infections. To prevent large losses during the reproduction of commercial objects, antibiotic substances have been used for many years, which led to the development of resistance to them in a large number of microorganisms. To prevent bacterial resistance to antibiotics from leading to environmental disaster, it is necessary to look for safer ways to fight microbes. In recent years, green agrobiotechnology and probiotics in particular have become increasingly popular. These preparations can be used prophylactically to prevent the development of infections [1].

Shrimp aquaculture is one of the fastest growing branches of aquatic animal husbandry, the total production of which is estimated at millions of tons per year [2]. The problems of breeding these crustaceans include water pollution, lack of quality feed and outbreaks of diseases of microbial etiology [3]. To address these latter challenges, researchers are actively exploring the effectiveness of beneficial microbial agents as a probiotic supplement for shrimp.

In the course of a series of experiments carried out by various scientists from Iran [4], Korea [5], China [6], India [7], Thailand [8], the island of Taiwan [9], the positive

\footnotetext{
*Corresponding author: gelishka96@mail.ru
} 
dynamics of faster growth and digestibility of food in shrimp, as well as increased survival rates and immune response compared to control groups.

The probiotic preparations they added most often included various strains of the genus Bacillus. Modern scientists are trying to expand the range of bacillus species for use in aquaculture. Therefore, researchers are studying the safety and antagonistic activity of the species B. pumilus [10], B. toyonensis [11] and other microorganisms.

In view of all these facts, development of a multicomponent probiotic preparation based on antagonistically active strains of bacilli is relevant for development of organic agriculture, including aquaculture.

The aim of this paper is to study the effectiveness of use of a new probiotic preparation based on bacilli in the cultivation of Macrobrachium rosenbergii shrimp.

\section{Materials and Methods}

An experimental batch of probiotic was obtained on the basis of the Engineering Center Prombiotech, Altai State University. The multicomponent probiotic preparation is a powder consisting of lyophilized bacterial concentrates and maltodextrin. The active component of the biological product is a consortium based on patented antagonistically active strains $B$. toyonensis B-13249 and B. pumilus B-13250 (Pat. No. 2693439 RF and Pat. No. 2694522 $\mathrm{RF})$. The titer of bacilli in the finished preparation is not less than $1 \times 10{ }^{10} \mathrm{CFU} / \mathrm{g}$ [12].

The probiotic study was carried out on a private farm located in the Republic of Kazakhstan, in the vicinity of Karaganda. For the experiment, we used the offspring of a female Rosenberg shrimp (M. rosenbergii), which was divided into 2 groups: control (fed with Artemia franciscana $L$. incubated without the addition of probiotic) and experimental one (fed with brine shrimp incubated with addition of probiotic, i.e. "enriched" brine shrimp). Arsal LLC provided Artemia batch, and it was received from the Kuchuk Lake (Altai Krai, Yarovoe). Each group consisted of 200 shrimp larvae, which were raised in the same aquarium systems of 600 liters each.

Hydrochemical parameters $(\mathrm{pH}$, temperature, O2, concentration of nitrogenous substances $\left(\mathrm{NH}_{3} / \mathrm{NH}_{4}^{+}, \mathrm{NO}_{2}, \mathrm{NO}_{3}{ }^{-}\right)$were maintained within the normal range throughout the experiment [13].

Artemia nauplii were used as the only food. The probiotic was added at 20 hours of incubation of Artemia cysts, when the bulk of nauplii began to hatch, in an amount of $1 \mathrm{~g}$ per $100 \mathrm{~g}$ of dry cysts with a total incubation duration of 24 hours. In one pool about $20 \mathrm{~g}$ of cysts per day was added. When feeding shrimp at a later stage of development (about 15 days of rearing), nauplii were used for 48 hours of incubation. The probiotic was also added at 20 hours of incubation of cysts together with $0.5 \mathrm{ml}$ of a suspension of live spirulina per 1 liter of incubation solution ( $5 \mathrm{ml}$ per pool/day). Spirulina was introduced to increase the mobility of nauplii in order to attract the attention of shrimp larvae.

The shrimp molts were fixed visually so as not to injure the animals. If in the total mass was found at least one shrimp that had passed the molt, it was considered that the entire group had passed this molt. Because from the molt beginning, the whole group finishes it within 24 hours.

A homogeneous group of 1000 shrimp postlarvae, not involved in the previous experiment, was divided equally into experimental and control groups. Each group was grown for a month in a separate closed system with a volume of 600 liters. Wherein, a probiotic in a quantity of $5 \mathrm{~g}$ was added once a week to the water circulating in the RAS (circulating water). The shrimp were fed with dry food. During the month, measurements of the main nutrients - indicators of biological treatment - ammonium $\left(\mathrm{NH}_{3} / \mathrm{NH}_{4+}\right)$, nitrite $\left(\mathrm{NO}_{2}\right)$ and nitrate $\left(\mathrm{NO}_{3}-\right)$ nitrogen were carried out on a regular basis. Measurements were 
carried out using drop tests (colorimetry for ammonium with Nessler's reagent, for nitrites and nitrates according to Bendschneider and Robinson [14].

\section{Results and Discussion}

According to the obtained data, in the experimental group, an earlier exit from the larval stage was observed - on the 18th day. In the control group - on the 28-th day (Fig. 1). The survival rate in both groups did not differ significantly and was more than $90 \%$.

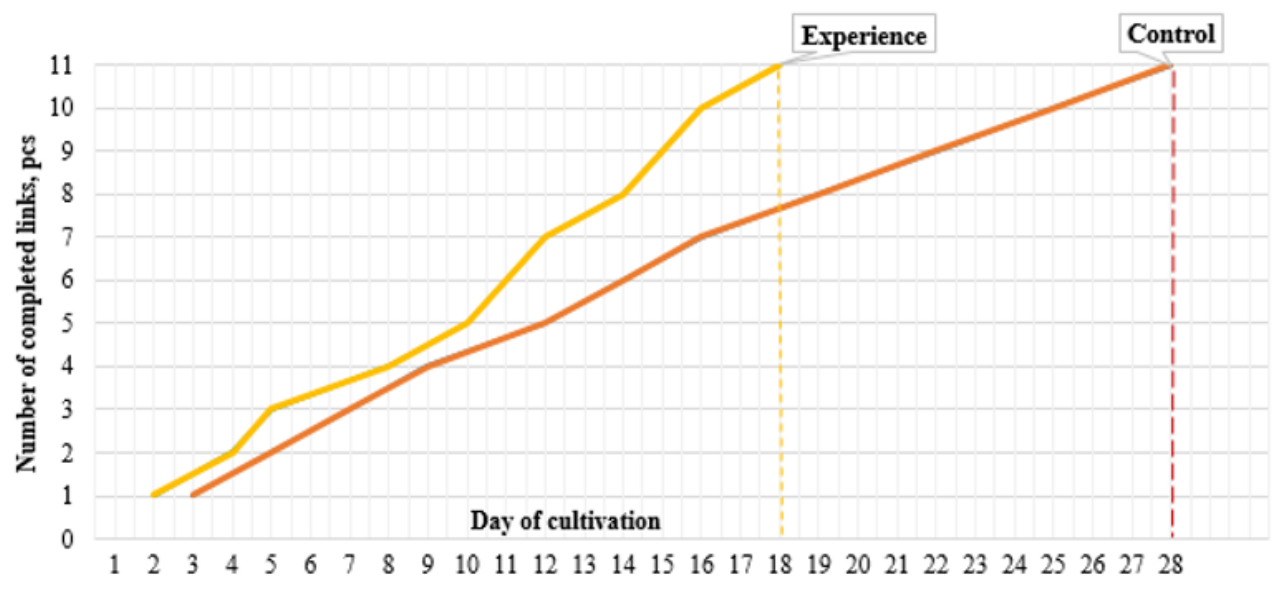

Fig. 1. The timing of the completion of the metamorphosis of $M$. rosenbergii larvae in the experimental and control groups

During the early stages of development, shrimp are demanding on the mobility of the food. In this regard, the technology of feeding shrimp prelarvae with live, newly hatched brine shrimp nauplii is widely used in aquaculture [15]. The incubation solution for $A$. franciscana is a very favorable environment for development of any, including unfavorable microflora that affects the quality of the final product. For this reason, breeders of brine shrimp are interested in adding probiotic and prebiotic preparations to their product to reduce the possible development of pathogens and transfer them to shrimp prelarvae [16]. The hatched Rosenberg shrimp larva goes through 11 different larval stages to become postlarva. According to the reference data, this process takes approximately 22-45 days [17]. According to the obtained data, in the experimental group of shrimps the molting process was completed in 18 days, which is 10 days faster than in the control group. This result indicates a positive effect of the probiotic preparation on the rate of passage of the larval stage in $M$. rosenbergii. This may be due to the antagonistic properties of bacilli in the probiotic in relation to shrimp pathogens, an increase in the efficiency of food assimilation by the larvae due to the synthesis of various digestive enzymes by microbes, and etc. However, more studies is needed to confirm these hypotheses.

In accordance with the data in Figure 2, the probiotic has a positive effect on the hydrochemical parameters of water. The concentration of ammonium $\left(\mathrm{NH}_{4}\right)$ and nitrite $\left(\mathrm{NO}_{2}\right)$ nitrogen in the control system by the end of the experiment reached the upper limit of the norm $(0.5 \mathrm{mg} / \mathrm{l})$, but not in the experiment. At a normal concentration of $\mathrm{NO}_{3}$ nitrate up to $50 \mathrm{mg} / \mathrm{l}$ in the control unit on the 24 th day of the experiment, a peak value of $60 \mathrm{mg} / \mathrm{l}$ was recorded. In the experimental installation this indicator did not exceed $40 \mathrm{mg} / \mathrm{l}$. 


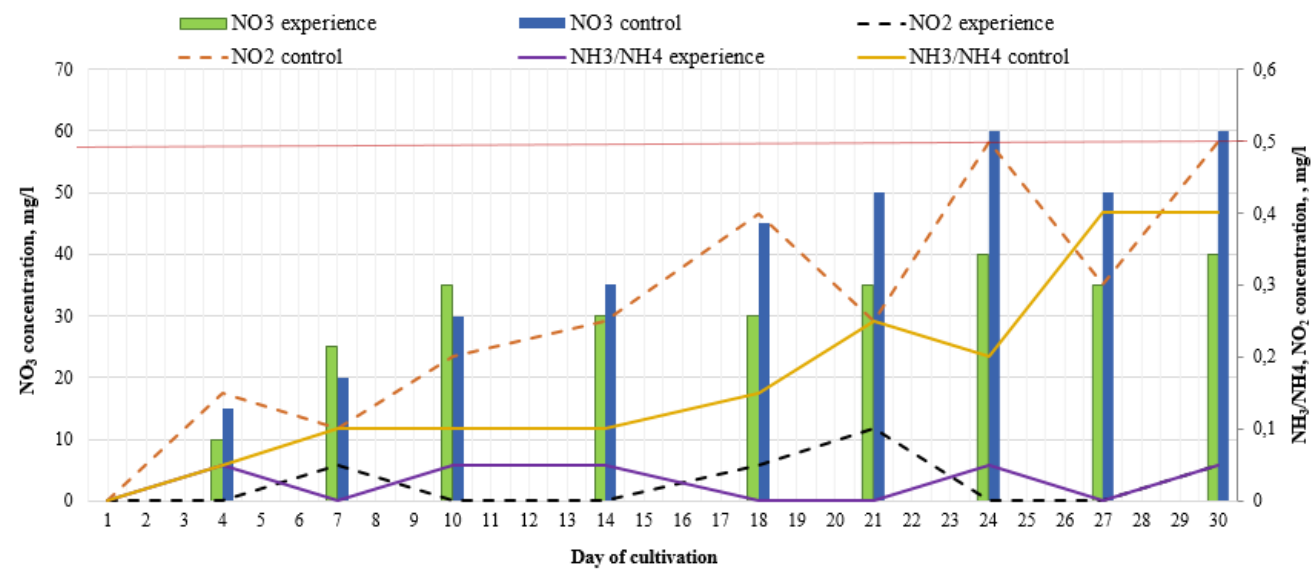

Fig. 2. Hydrochemical regime in experimental and control systems

Crustacean larvae are demanding on water quality and are classically controlled for ammonium, nitrites and nitrates. Since nitrogen-containing compounds in high concentrations have a detrimental effect on the development of shrimp [18]. The probiotic preparation under study reduces the concentration of toxic compounds in water as compared to the control. This contributes to improving the productivity of the system. Improvement of the hydrochemical parameters of water due to the addition of a probiotic to it indicates of the broader functional properties of the biological product.

\section{Conclusions}

Therefore, a new probiotic preparation based on strains B. toyonensis B-13249 and B. pumilus B-13250 promotes an earlier exit from the larval stage of $M$. rosenbergii (on day 18), as well as an improvement in the hydrochemical parameters of water in the RAS compared to the control. So, this biological product can be effectively used in agroindustrial complexes developing organic agriculture. The dosage of the probiotic when applied with brine shrimp as feed for shrimp is 1 gram per 100 grams of dry cysts. The dosage of the probiotic when the RAS is added to the water is $5 \mathrm{~g}$ per 600 liters of circulating water once a week.

\section{References}

1. L.V. Shulgina, E.V. Yakush, Yu.P. Shulgin, V.V. Shenderyuk, N.N. Chukalova, L.P. Baholdina, Izvestiya TINRO, 181(2), 216 (2015)

2. S. Tepaamorndech, K. Chantarasakha, Y. Kingcha, S. Chaiyapechara, M. Phromson, M. Sriariyanun, W. Visessanguan, Fish Shellfish Immunol., 86, 4 (2018)

3. D. Srinivas, Ch. Venkatrayalu, Adv. Appl. Sci. Res., 7(2), 49 (2016)

4. S. Ziaei-Nejad, M.H. Rezaei, G.A. Takami, D.L. Lovett, A. Mirvaghefi, M. Shakouri, Aquac., 252(2-4), 516 (2006)

5. A. Sekar, M. Kim, H. Jeon, K. Kim, BB Rep., 19, 100663 (2019)

6. K. Amoah, Q.C. Huang, B.P. Tan, S. Zhang, S.Y. Chi, Q.H. Yang, X.H. Dong, Fish Shellfish Immunol., 87, 796 (2019)

7. S. Fernandes, S. Kerkar, J. Leitao, A. Mishra, Probiotics Antimicrob. Proteins, 11(4), 1309 (2019) 
8. S. Tepaamorndech, K. Chantarasakha, Y. Kingcha, S. Chaiyapechara, M. Phromson, M. Sriariyanun, W. Visessanguan, Fish Shellfish Immunol., 86, 4 (2018)

9. Y.C. Wang, S.Y. Hu, C.S. Chiu, C.H. Liu, Fish Shellfish Immunol., 84, 1050 (2019).

10. H.T, Truong, N.N. Tri, N. Ong, M. Quya, R. Fotedarc, K. Kannikad, S. Unajake, N. Areechon, Fish Shellfish Immunol., 60, 391 (2017)

11. F. Feliatra, Nursyirwani, A. Tanjung, D.S. Adithiya, M. Susanna, I. Lukystyowati, IOP Conf. Ser.: Earth Environ. Sci., 116, 012034 (2018)

12. A.V. Malkova, I.Yu. Evdokimov, M.V. Shirmanov, A.N. Irkitova, D.E. Dudnik, Proc Univ Appl Chem Biotechnol, 11(3), 393 (2021)

13. M.B. New, Farming freshwater prawns (Marlow, United Kingdom, 2002)

14. V.V. Sapozhnikov, A.I. Agatova, N.V. Arzhanova, N.V. Mordasova, N.M. Lapina, V.L. Zubarevich, O.N. Lukyanova, N.I. Torgunova, Guidelines for the chemical analysis of sea and fresh waters (RuFIR, Moscow, 2003)

15. T.D.N.J. Maldonado-Montiel, L.G. Rodriguez-Canche, Rev. biol. trop., 53, 3 (2005)

16. H. Hamsah, W. Widanarni, A. Alimuddin, M. Yuhana, Jr. M. Zairin, AACL Bioflux, 10(1), 8 (2017)

17. M.B. New, W.C. Valenti, Freshwater Prawn Culture (Blackwell Science, Oxford, England, 2001)

18. W.J. Wasielesky, L.H. Poersch, T.G. Martins, K.C. Miranda-Filho, Braz. J. Biol., 77 (3), 558 (2017) 